\title{
Immigrant Legal Status Disparities in Health Among First- and One-point-five-Generation Latinx Immigrants in California
}

\author{
Erin R. Hamilton ${ }^{1}$ (D) $\cdot$ Caitlin Patler $^{1} \cdot$ Robin Savinar $^{1}$
}

Received: 22 June 2020 / Accepted: 3 December 2021 / Published online: 13 December 2021

(c) The Author(s) 2021

\begin{abstract}
Restrictive US immigration laws and law enforcement undermine immigrant health by generating fear and stress, disrupting families and communities, and eroding social and economic wellbeing. The inequality and stress created by immigration law and law enforcement may also generate disparities in health among immigrants with different legal statuses. However, existing research does not find consistent evidence of immigrant legal status disparities in health, possibly because it does not disaggregate immigrants by generation, defined by age at migration. Immigration and life course theory suggest that the health consequences of non-citizen status may be greater among 1.5-generation immigrants, who grew up in the same society that denies them formal membership, than among the 1st generation, who immigrated as adolescents or adults. In this study, we examine whether there are legal status disparities in health within and between the 1st generation and the 1.5 generation of 23,288 Latinx immigrant adults interviewed in the 2005-2017 waves of the California Health Interview Survey. We find evidence of legal status disparities in heart disease within the 1st generation and for high blood pressure and diabetes within the 1.5 generation. Non-citizens have higher rates of poor self-rated health and distress within both generations. Socioeconomic disadvantage and limited access to care largely account for the worse health of legally disadvantaged 1st- and 1.5-generation Latinx adults in California.
\end{abstract}

Keywords Immigrants · Legal status · Health disparities $\cdot 1.5$ generation · Latinx · California

Restrictive immigration laws and law enforcement generate fear and stress, disrupt families and communities, and undermine the economic wellbeing of immigrants

Erin R. Hamilton

erhamilton@ucdavis.edu

1 Department of Sociology, University of California, Davis, USA 
in the United States (Cardoso et al., 2021; Enriquez, 2020; Gándara \& Ee, 2021; Gomez Cervantes \& Menjívar, 2020; Lopez, 2019; Menjívar \& Abrego, 2012; Valdivia, 2019). Because stress, social disruption, and economic disadvantage are key mechanisms linking social conditions to health, scholars have identified US immigration law as a social determinant of health (Asad \& Clair, 2018; Castañeda et al., 2015; Martinez et al., 2015; Taylor, 2020; Torres \& Young, 2016).

Yet, while research finds that changes to immigration policy impact immigrant health (Novak et al., 2017; Patler \& Laster Pirtle, 2018; Ro et al., 2020; Torche \& Sirois, 2019), research on health disparities among immigrants in various legal statuses have found inconsistent results (Bacong \& Sohn, 2020; Hamilton et al., 2019; Ro \& Van Hook, 2021).

One reason research on legal status disparities in health may produce inconsistent results is that studies have only begun to address the considerable heterogeneity among immigrants, especially differences that may affect the relationship between legal status and health (Ro \& Van Hook, 2021; Young \& Pebley, 2017). Life course and immigrant integration theories suggest that one of the most important ways that the consequences of legal status may vary among immigrants is by age at migration, specifically whether migration occurs before or after childhood. The life course timing of migration is so fundamental to the immigrant experience that scholars refer to immigrants who arrive prior to adolescence (defined as before age 13) as a distinct group: the 1.5 generation (Rumbaut, 2004). The 1.5 generation's experience is in many ways more similar to that of the 2 nd generation, who are born to immigrants in the country of destination, than to the experience of the 1st generation, who immigrate in adolescence or adulthood. The key difference between the 1.5 and 2 nd generations is citizenship: the 2nd generation are citizens by birth. Because the 1.5 generation grows up and forms primary attachments in the country of destination, for 1.5-generation non-citizen immigrants, the exclusions of immigration law and threat of immigration enforcement create an especially painful and alienating experience that has consequences on schooling and work, connections with others, and identity (Abrego, 2011; Gleeson \& Gonzales, 2012; Gonzales, 2011; Patler, 2018b; Vaquera et al., 2017). The experience of growing up without status likely has unique consequences for health, as well, but research on legal status disparities in health has heretofore grouped the 1 st and the 1.5 generations.

In this study, we examine legal status disparities in health within and between 1st-generation and 1.5-generation adult immigrants of Latinx origins living in California. ${ }^{1}$ Specifically, we compare the health of naturalized US citizens, lawful permanent residents (LPRs), and non-citizen, non-LPRs, who are likely to be undocumented. ${ }^{2}$ We use data from Latinx immigrant adults interviewed in the 2005-2017 waves of the California Health Interview Study (CHIS), which provides a representative sample of Latinx immigrant adults living in California during this period.

\footnotetext{
1 We use the term Latinx to refer to people who were born in a country in Latin America. We opt to use the term "Latinx" rather than "Latino" or "Latino/a" to maintain gender neutrality.

2 As described below, an estimated 88-93\% of Latinx non-citizen immigrants in California are undocumented (Vargas Bustamante et al., 2012). For simplicity, hereafter we refer to this group as "undocumented".
} 
Because we are interested in broad patterns of health inequality, rather than specific causes of illness, we examine patterns across nine self-reported health outcomes measured in the CHIS, including chronic conditions, current conditions, self-health assessment, and mental distress.

\section{Background}

\section{Immigrant Legal Status and Health}

Immigrant rights range across what Joseph (2020) calls the "documentation status continuum" (see also Bean et al., 2015; Oropesa et al., 2015; Patler, 2018a; Waters et al., 2015). The rights granted by immigrant legal status dictate how long someone can be in the United States, the ability to transition into other (more permanent) legal statuses, the right to sponsor family for immigration, the right to work or change employers, the right to travel in and out of the United States, and the right to access federally funded services, such as health insurance, welfare benefits, and student loans. Among immigrants, those with the greatest rights are naturalized citizens, who through naturalization obtain the same rights as US-born citizens. LPRs (also called "green card" holders) can remain in the United States indefinitely, have the right to work for most US employers, and can sponsor some family members for immigration, but they cannot vote and are subject to deportation if convicted of certain crimes. Individuals with non-citizen, non-LPR status have still fewer rights. This group includes temporary visa holders (e.g., students, temporary workers, and refugees for the first year of residence) whose right to work and length of status depend on the terms of the visa, and those with "liminal" (Menjívar, 2006) statuses such as temporary protected status (TPS) or deferred action for childhood arrivals (DACA) status. Undocumented immigrants, who entered without inspection or overstayed a temporary visa, have the fewest rights. Most significantly, undocumented immigrants do not have the right to work and are subject to removal on the basis of their immigration status.

The rights granted by one's position on the documentation status continuum determine three key mechanisms for health: socioeconomic status and resources, access to health care, and stress. Immigrant legal status is associated with socioeconomic disadvantage, especially between undocumented and other immigrants, as a result of legal barriers to the US labor market, post-secondary education, and social safety net programs designed to keep people out of poverty (Amuedo-Dorantes \& Antman, 2016; Borjas, 2011; Gleeson, 2010; Phillips \& Massey, 1999). As a result of barriers to legal work, as well as federal laws that bar non-citizen immigrants from Medicaid and other federally funded insurance programs, undocumented immigrants have far lower rates of insurance coverage and access to health care (Gomez Cervantes \& Menjívar, 2020; Marshall et al., 2005; Vargas Bustamante et al., 2012). Not only does non-citizen legal status present formal barriers to socioeconomic opportunities and support, but also surveillance of immigrants and enforcement of immigration law by local and federal law enforcement creates substantial stress and fear in immigrant communities (Asad, 2020; Berk \& Schur, 2001; Dreby, 2015; 
Enriquez et al., 2018; García, 2018; Zayas et al., 2015). Immigration status therefore affects health through legal status-stratified systems of resources and opportunities, including health care, and the stress of immigration enforcement.

Because socioeconomic status, health care, and stress are key mechanisms linking social conditions to health, scholars have argued that immigration policy, or immigration status (itself determined by policy), is a social determinant of health (Asad \& Clair, 2018; Castañeda et al., 2015; Martinez et al., 2015; Taylor, 2020). A growing body of research examines whether the documentation status continuum results in health disparities among immigrants by legal status, but the research does not find evidence of consistent disparities (for a review, see Hamilton et al., 2019). This could be due to data constraints-particularly in the ability to sample undocumented immigrant populations and measure immigrant legal status in secondary data sources. Yet, studies using a range of methods and data sources arrive at similar conclusions — of few legal status disparities in health (Bacong \& Sohn, 2020; Flores et al., 2012; Hamilton et al., 2019; Iten et al., 2014; Kelaher \& Jessop, 2002; Marshall et al., 2005; Ro \& Hook, 2021; Swartz et al., 2017; Wen \& Maloney, 2014). Existing studies analyze a wide variety of data sources, including surveys, insurance claims, driver's license applications, medical records, birth records, and community samples. Because immigrant legal status is not commonly measured in population health data sources owing to its sensitive nature, many studies impute or use proxies for immigrant legal status, but other studies directly measure immigrant legal status in small, non-random samples of immigrants or in large, random, but unique samples of immigrants, such as farm workers. Studies also analyze a diverse set of measures of health, including chronic illness prevalence, incidence of disease and symptoms, clinical measures of high blood pressure and diabetes outcomes, selfreported health, and birth outcomes. Regardless of differences in data and measurement, studies find few consistent legal status disparities in health.

\section{Immigrant Generation, Legal Status, and Health}

As described above, the rights granted by one's position within the documentation status continuum can affect health through multiple mechanisms, especially socioeconomic status, health care, and the stress of immigration enforcement. Life course and immigrant integration theories suggest that while barriers to socioeconomic resources and health care are similar for 1st- and 1.5-generation immigrant adults, stress may function differently across generations, given differences in the primary institutions governing their lives (Abrego, 2006; Enriquez, 2020; Gleeson \& Gonzales, 2012; Gonzales, 2011), resulting in potentially different patterns of health between and within generations. For example, all children are protected by equal access to public K-12 education and, in some states like California after 2016, to state-funded health insurance coverage, regardless of their immigration status (Gleeson \& Gonzales, 2012). However, the institutions governing adult life-most notably, the labor market, but also health care-use immigrant legal status as a barrier to adult entry, regardless of an immigrant's level or location of education attainment. Although undocumented 1.5-generation immigrants are educated in US schools that foster a norm of meritocracy, legal barriers to work mean that their ambitions, efforts, and talents in school are not rewarded in the labor market (Abrego, 2011; Gleeson \& Gonzales, 2012; Gonzales, 2011). 
While material disadvantages - restricted socioeconomic opportunities and access to health care-likely undermine health in similar ways for adults in the 1st and 1.5 generations, the stress of immigration enforcement may be differently harmful for the 1.5 generation, who immigrated as children. Immigrants who arrive as children grow up and form primary attachments and identities in the United States (Abrego, 2011; Gleeson \& Gonzales, 2012; Patler, 2018b; Vaquera et al., 2017). Unlike their parents, 1.5-generation immigrants do not commonly have a frame of reference based in the origin country with which to compare and evaluate their experiences as immigrants. Instead, peers, institutions, and culture in the destination country form the frame of reference. 1.5-generation immigrants come to know local meanings regarding immigration - those based in a discriminatory ideology, policies, and actions-as they grow up amidst and are subject to them.

Research has shown that the circumstances of growing up in the United States, and forming primary attachments and identities there, amplify the indignity and harms of undocumented status. The implications of undocumented status become manifest at the transition to adulthood, as adolescents exit the K-12 school system and begin to engage with the institutions that govern adult life in the United States (Gonzales, 2011). Research on the experiences of undocumented 1.5-generation immigrants has found that "learning to be illegal" is akin to "awakening to a nightmare": one's identity, plans, hopes, and dreams confront the reality of formal exclusion from US institutions and the daily threat of legal action (Gonzales, 2011; Gonzales \& Chavez, 2012). Given the vast expansion of immigration law enforcement over the past several decades, recent research has also suggested that LPRs may also experience heightened legal statusrelated distress that could make their experiences more similar to those of undocumented immigrants than to naturalized citizens (Asad, 2020; Patler, 2018a).

At the same time that the transition to adulthood involves a shift into adult-governing institutions that formally exclude undocumented immigrants, it is also a critical period of development during which lifelong health habits and patterns are established. Torres and Young (2016) applied life course theory to understand how the consequences of immigrant legal status on health may be especially harmful during the transition to adulthood. Adolescence and early adulthood are periods during which individuals establish health habits, such as smoking, and in which health status is often set, with lifelong consequences for health and socioeconomic status (Harris, 2010). The coupling of the transition to adulthood with "awakening" to legal exclusion may therefore be especially harmful for the health of 1.5-generation non-citizen immigrants.

\section{Research Questions and Expectations}

We ask two distinct research questions in this study. First, we ask whether there are legal status disparities within the 1st and the 1.5 generations of adult Latinx immigrants in California. Because legal status determines one's rights, including access to socioeconomic opportunities and health care, and stress imposed by the threat of immigration enforcement, we expect to observe legal status disparities in health among both generations. Second, we ask whether there are greater legal status disparities in health among the 1.5 than among the 1st generation of adult Latinx 
immigrants in California. Because the 1.5 generation grows up in the same society that denies them membership and equal rights, we expect the harms of non-citizen immigration status to be greater for the health of 1.5 generation immigrants than the harms of non-citizen immigration status among the 1 st generation.

\section{Data and Methods}

We use data from the 2005-2017 CHIS, a telephone survey of California's residential, non-institutionalized population collected by UCLA's Center for Health Policy Research (CHPR). The CHIS uses a dual-frame, multi-stage sampling design that draws from landline and cell phone numbers in California. The survey randomly selects one adult (age 18 and older) from each sampled household. Our analytical sample includes 23,288 Latinx immigrant adult (ages 18-65) respondents interviewed between 2005 and 2017, the years for which our key variables were consistently asked in the CHIS. Latinx immigrants are respondents who report that they were born outside the United States in countries in Latin America or the Spanishspeaking Caribbean. We define the 1.5 generation as immigrants who arrived to the United States at age 12 or younger because primary socialization occurs prior to adolescence (Rumbaut, 2004). The majority of Latinx immigrants in the CHIS are 1st generation $(82 \%, n=19,123)$, but by combining 12 years of data, we obtain a sufficient sample of 1.5 -generation immigrants $(n=4,165)$. We use survey weights to adjust for the complex sample design. The CHPR Data Access Center imputed missing values on all variables used in our analysis.

The CHIS is especially useful for our purposes because it includes a more detailed series of questions to determine immigrant legal status than national health surveys such as the National Health Interview Survey or the Behavioral Risk Factor Surveillance System. The CHIS asks foreign-born respondents first if they are citizens; then it asks those who are not citizens if they are LPRs. ${ }^{3}$ Respondents who answer no to both questions include undocumented immigrants, refugees who have not yet adjusted status to LPR, temporary visa holders, and immigrants with discretionary status (such as DACA). The large majority of this group is likely undocumented; in prior years, studies estimated that $88-93 \%$ of Latinx non-citizen-nonLPRs in California were undocumented (Vargas Bustamante et al., 2012). ${ }^{4}$ Many studies have used the CHIS to examine the health status and access to health care of undocumented immigrants (e.g., Bacong \& Sohn, 2020; Oropesa et al., 2015; Patler et al., 2019; Pourat et al., 2014; Vargas Bustamante et al., 2012).

\footnotetext{
${ }^{3}$ The National Health Interview Survey does not ask the second question, meaning that analysts cannot differentiate LPRs from other immigrants among non-citizens. The Behavioral Risk Factor Surveillance System does not ask about nativity. Citizens make up just under half (45\%) of immigrants in the United States, and LPRs make up an additional 27\%, meaning LPRs are more than half of non-citizen immigrants (Radford, 2019).

${ }^{4}$ Vargas Bustamante et al. (2012) reported that the share of Latinx non-citizen, non-LPRs who are temporary visa holders in California is 7\%; in 2015-2016, in the CHIS, the share was $12 \%$. For Asian immigrants, the share of temporary visa holders among non-citizen-non-LPR immigrants in the United States is much higher (44\%) (Zong et al., 2019).
} 
California in this period provides a useful context for studying immigrant health disparities because it is the state with the largest immigrant population (twice as large as the second-largest state immigrant population, in Texas) and the greatest share of the population that is of immigrant origin $(27 \%$, followed by $23 \%$ in New Jersey and 22\% in New York) (Migration Policy Institute 2021). In California, $48.5 \%$ of immigrants are of Latinx origins and 46.4\% are non-citizens (MPI 2021). Population data from California will therefore provide a large sample of Latinx immigrants with substantial variation across legal statuses-as is true in the CHIS. Still, as a context within which to study the harms of immigration enforcement, the state in this period is unique for its efforts to extend services and protections to undocumented immigrants. Since 2000, the CA Legislature passed a number of laws expanding immigrant rights in this period, including, for example, the 2011 California Dream Act, which gave access to state funds for college tuition assistance for undocumented residents; 2013's AB60, which allows undocumented immigrants to apply for driver's licenses; and the 2014 California TRUST Act, which limited the collaboration between local law enforcement and federal immigration enforcement. In this context, it may be that non-citizen immigration status is not as harmful to health as in other states, such as Arizona or Alabama, where state law has taken the opposite approach. In other words, our estimates of group differences may not generalize beyond California or may be conservative estimates of group differences in less welcoming state climates.

We analyze a broad set of measures of health. Population health science does not give preference to particular health outcomes for the analysis of social inequality or social determinants of health (Hummer \& Hamilton, 2019). Furthermore, central theories of health disparities, such as fundamental cause theory, emphasize that social disparities in health vary consistently across a diverse set of outcomes (Link $\&$ Phelan, 1995). It is also important to measure a diverse set of outcomes because of the unique biases that different measures of health present. For instance, in survey data such as the CHIS, questions about chronic conditions ask if the condition has been diagnosed by a health professional, which may result in under-measurement among groups with less access to health care, such as undocumented immigrants (Pourat et al., 2014). Other measures, such as self-rated health, may reflect language and cultural differences in health assessment (Finch \& Vega, 2003). With this guidance in mind, we make use of all questions regarding physical and mental health available in the CHIS in the 2005-2017 waves. We measure four chronic conditions by respondents' reports of whether a health care professional has ever told them they have: (1) heart disease, (2) high blood pressure, (3) asthma, and (4) diabetes. We measure three current conditions: (5) asthma (whether respondent reports having had an episode of asthma or an asthma attack in the past 12 months), (6) one or more visits to the emergency room in the past year, and (7) obesity [measured as a body mass index (BMI), or reported weight in kilos divided by reported height in meters squared, of 30 or greater]. These measures are useful supplements to chronic conditions because they capture current health and do not depend on a doctor diagnosis. We also analyze (8) self-rated health as a global measure of physical and mental health. Respondents reported whether their health was excellent, very good, good, fair, or poor. We dichotomized the 5-point scale into a binary variable $(1=$ fair 
or poor health; $0=$ good, very good, or excellent health). ${ }^{5}$ Finally, we use (9) the respondent's score on the Kessler 6-question (K6) psychological distress scale to analyze a dichotomous measure of moderate or severe distress (K6 $\geq 5$ ) (Prochaska et al., 2012). The K6 scale includes six questions with Likert-scale responses assessing the recent frequency of mental health symptoms such as nervousness, hopelessness, and restlessness. The score is a count that ranges from zero to 24 points. ${ }^{6}$

We analyze each of the nine binary outcomes using linear probability models. Coefficients from linear probability models can be interpreted as the effect of a oneunit change in an independent variable on the probability of the outcome. ${ }^{7}$ We use coefficients from the first model, which controls for age and survey year, to predict the probability of each outcome for each generation-legal status group, which we present in a series of graphs. Age controls account for the younger age distribution of undocumented immigrants, as compared to LPRs and naturalized citizens (see Table 1).

We then present results from a model that additionally controls for demographic characteristics, socioeconomic status, and access to health care. With this model, we assess whether differences across legal status and generational groups in these measured characteristics - especially socioeconomic status and health care-account for group differences in health. The model adds controls for characteristics that research has shown are associated with health, generation, and immigrant status, including gender, marital status (married versus not), education (less than high school, high school or GED, some college, or BA or higher), the household income-to-poverty ratio (expressed as a percentage of the federal poverty line), Mexican ethnicity, current insurance coverage (public or private, versus none), and having a usual source of health care (Bacong \& Sohn, 2020; Finch \& Vega, 2003; Pourat et al., 2014; Ro \& Hook, 2021; Vargas Bustamante et al., 2012; Young \& Pebley, 2017). We present these results as regression coefficients and as average marginal effects for key group contrasts.

\section{Results}

Table 1 shows the average characteristics of each of the six groups of Latinx immigrant adults in the CHIS between 2005 and 2017 (naturalized citizens, LPRs, and undocumented, across the 1 st and 1.5 generations). The table reveals that there are significant differences in age, marital status, education, income, years in the United States, Mexican ethnicity, Spanish language, insurance coverage, and usual source

\footnotetext{
5 We also conducted all analyses on the continuous self-rated health scale and on health defined as poor, fair, or good versus very good or excellent, and results (not shown) were similar.

6 The CHIS K6 question asks, "About how often during the past 30 days did you... feel nervous-Would you say all of the time, most of the time, some of the time, a little of the time, or none of the time? ... feel hopeless? ...feel restless or fidgety? ...feel so depressed that nothing could cheer you up? ...feel that everything was an effort? ...feel worthless?" We also analyzed the K6 scale as a continuous (count) outcome, and results (not shown) were consistent.

7 We compared estimates from the logistic regressions to estimates from linear probability models; results (not shown) were consistent.
} 
Table 1 Weighted and age- and survey year-adjusted means and percent distributions of demographic and social characteristics of Latinx adults in California, 2005-2017, by legal status, within the 1st and 1.5 generations

\begin{tabular}{|c|c|c|c|}
\hline & Naturalized citizen & LPR & Undocumented \\
\hline \multicolumn{4}{|l|}{ Panel A. 1st generation } \\
\hline Age (mean) & $49.7 * \mathrm{a}$ & $44.4 * \mathrm{a}$ & $37.8^{* \mathrm{a}}$ \\
\hline Male (\%) & $46.7 *$ & 50.4 & $51.8^{*}$ \\
\hline Married (\%) & $73.0^{* \mathrm{a}}$ & $65.5^{* \mathrm{a}}$ & $44.4 * \mathrm{a}$ \\
\hline \multicolumn{4}{|l|}{ Education (\%) } \\
\hline Less than HS & $50.4 * \mathrm{a}$ & $65.4^{\mathrm{a}}$ & $66.7 * \mathrm{a}$ \\
\hline HS/GED & $23.9^{* \mathrm{a}}$ & $18.9^{* \mathrm{a}}$ & $21.6^{\mathrm{a}}$ \\
\hline Some college & $13.0^{* \mathrm{a}}$ & $8.0^{\mathrm{a}}$ & $6.5^{* \mathrm{a}}$ \\
\hline BA or higher & $12.7 * \mathrm{a}$ & $7.7^{*}$ & $5.2 *$ \\
\hline Income-to-poverty ratio (mean) & $2.5^{* \mathrm{a}}$ & $1.7 * \mathrm{a}$ & $1.2^{* \mathrm{a}}$ \\
\hline Years in the US (mean) & $27.3^{* \mathrm{a}}$ & $20.4^{* \mathrm{a}}$ & $13.5^{* \mathrm{a}}$ \\
\hline Mexican (\%) & $73.0 *$ & 79.5 & $80.2 * \mathrm{a}$ \\
\hline Interview in Spanish & $66.0^{* \mathrm{a}}$ & $85.9^{* \mathrm{a}}$ & $92.4 * \mathrm{a}$ \\
\hline Currently insured (\%) & $79.4 * \mathrm{a}$ & $69.7 * \mathrm{a}$ & $48.3^{*}$ \\
\hline Has usual source of care (\%) & $81.1^{*}$ & $70.9 *$ & $58.5 *$ \\
\hline Sample size & 6314 & 6447 & 6362 \\
\hline \multicolumn{4}{|l|}{ Panel B. 1.5 generation } \\
\hline Age (mean) & $38.4^{*}$ & $33.0 *$ & $26.1 *$ \\
\hline Male $(\%)$ & 49.0 & 53.1 & 44.3 \\
\hline Married (\%) & $51.4^{*}$ & $35.3 *$ & $24.2^{*}$ \\
\hline \multicolumn{4}{|l|}{ Education (\%) } \\
\hline Less than HS & $12.6^{*}$ & 27.3 & $27.5^{*}$ \\
\hline HS/GED & 29.4 & $29.7 *$ & $48.9^{*}$ \\
\hline Some college & 31.7 & $31.8^{*}$ & $19.7^{*}$ \\
\hline BA or higher & $26.3^{*}$ & $11.2^{*}$ & $3.9 *$ \\
\hline Income-to-poverty ratio (mean) & $3.6^{*}$ & $2.4^{*}$ & $1.6^{*}$ \\
\hline Years in the US (mean) & $32.8^{*}$ & $26.5^{*}$ & $19.6^{*}$ \\
\hline Mexican $(\%)$ & $73.6^{*}$ & $82.5^{*}$ & $91.3^{*}$ \\
\hline Interview in Spanish & $9.3^{*}$ & 26.1 & $31.0^{*}$ \\
\hline Currently insured (\%) & $85.0^{*}$ & $76.0^{*}$ & $52.2^{*}$ \\
\hline Has usual source of care (\%) & $82.8^{*}$ & 70.8 & $64.3^{*}$ \\
\hline Sample size & 2723 & 998 & 444 \\
\hline
\end{tabular}

${ }^{\mathrm{a}}$ Indicates mean is statistically different at $p<0.05$, comparing 1 st to 1.5 generation within each legal status group

*Indicates mean is statistically different at $p<0.05$, comparing naturalized citizens to LPRs; LPRs to undocumented; and undocumented immigrants to naturalized citizens within each generation

of care between and within immigrant generations by legal status. On a whole, undocumented immigrants and LPRs are less advantaged than naturalized citizens, and 1st-generation immigrants are less advantaged than 1.5-generation immigrants. 
For example, two-thirds of undocumented 1st-generation Latinx immigrants have less than a high school education, a significantly higher share than 1st generation citizens (half of whom have a less than a high school education). However, all groups of 1.5-generation Latinx immigrants are less likely to have less than a high school education than 1st-generation citizens: about a quarter of undocumented and LPR 1.5-generation immigrants have less than a high school education, and $12.6 \%$ of 1.5-generation citizens have less than a high school education. A second finding of note is that LPRs and undocumented immigrants tend to be more similar to each other than either group is to citizens. Within both generations, citizens are older, are more likely to be married, are better educated, have higher income, have been in the United States more years, are less likely to be Mexican, are less likely to answer the interview in Spanish, are more likely to be insured, and are more likely to have a usual source of health care, than the other two groups.

Figure 1 shows age- and year-adjusted predicted rates (probabilities estimated from Model 1 in Table 3, converted to percentages) of nine health outcomes among adult Latinx immigrants in California across legal status and generation. Consistent with previous research, patterns of health outcomes do not vary in an obvious or consistent way across outcomes. However, some tentative conclusions can be drawn from the graphs. There are higher predicted rates of some outcomes-heart disease, high blood pressure, diabetes, poor health, and mental distress-among non-citizens (LPRs and undocumented immigrants) than citizens, though in some instances the confidence intervals are overlapping. For heart disease, citizens in both generations have lower rates than non-citizens; in the 1st generation, $2.8 \%$ of citizens report ever being diagnosed with heart disease, compared to $4.4 \%$ of LPRs and undocumented immigrants. In the 1.5 generation, the predicted rates are slightly higher, with the highest rate among LPRs (at 5.5\%), followed by undocumented immigrants (4.6\%) and citizens $(3.8 \%)$. Poor self-rated health shows a legal status gradient within both generations: $37 \%$ of undocumented 1.5-generation immigrants and $42 \%$ of undocumented 1st-generation immigrants rate their health as fair or poor (compared to good, very good, or excellent), compared to $33 \%$ of 1.5 -generation and $38 \%$ of 1 stgeneration LPRs and $21 \%$ of 1.5 -generation and $27 \%$ of 1 st-generation citizens. We also observe a legal status gradient in mental distress in the 1 st generation, but in the 1.5 generation, the larger difference is between citizens and non-citizens.

Table 2 provides statistical tests of differences in estimates (average marginal effects) across key groups, and Table 3 shows regression coefficients for the base and interacted terms (coefficients for covariates not shown). Table 2 shows statistically significant legal status differences in health on some outcomes within each generation, providing some support for our first research expectation of withingeneration legal status disparities in health. Within the 1st generation, LPRs and undocumented immigrants have significantly higher rates of heart disease, poor health, and mental distress than citizens. Undocumented immigrants also have higher rates of self-rated poor health than LPRs, but otherwise these two groups of non-citizens have similar rates of health outcomes within the 1 st generation. Within the 1.5 generation, there are differences in poor self-rated health and distress, as well as in high blood pressure and diabetes, between citizens and 


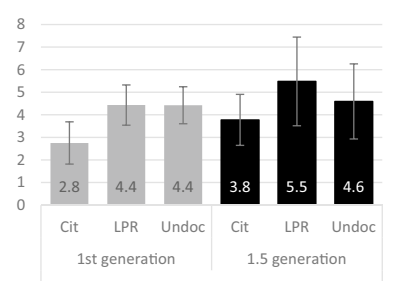

Heart Disease

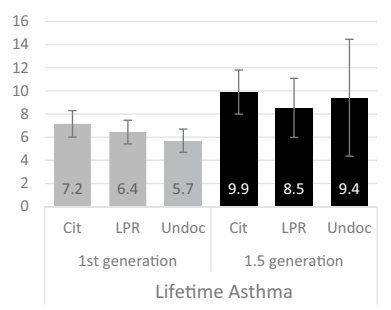

Lifetime Asthma

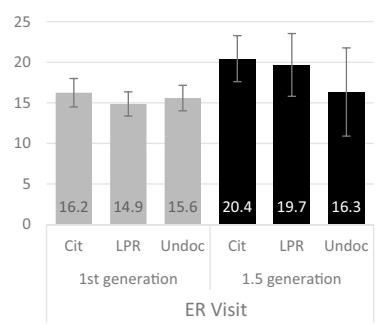

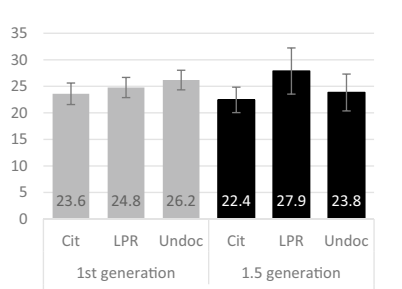

High Blood Pressure

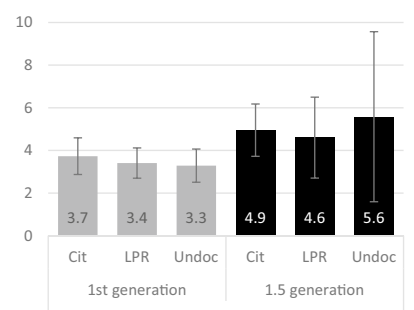

Current Asthma

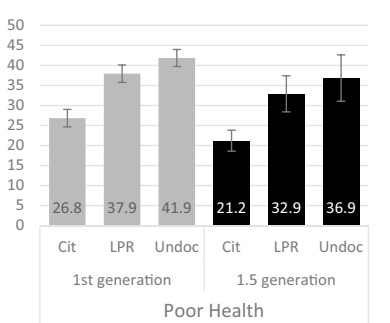

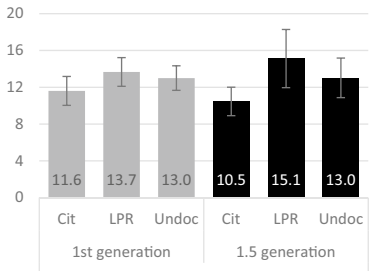

Diabetes
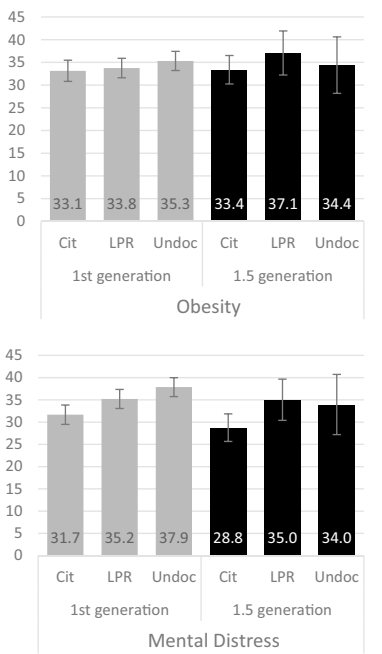

Fig. 1 Predicted rates of nine health outcomes by immigrant generation and legal status among Latinx adults in California, 2005-2017

non-citizens. In the 1.5 generation, LPRs and undocumented immigrants have similar rates of all nine measures of health.

Our second expectation was that legal status differences in health would be greater among the 1.5 generation than among the 1 st. The interaction term between immigrant generation and legal status in the models shown in Table 3 provides a test of this expectation. None of the interaction terms are significant for any outcome. In other words, the differences we observe in health across legal statuses in the 1st generation are not significantly different from the differences in health across legal status in the 1.5 generation, holding age and year of survey constant.

Model 2 in Table 3 controls for all measures in Table 1, with key contrasts shown in Panel B of Table 2. The two sets of results show that nearly all group differences are reduced in size and/or are imprecisely estimated in this model. This finding suggests that most group differences in health observed in Fig. 1 and Model 1 are driven by group differences in the characteristics included in the models and their associations with health. 


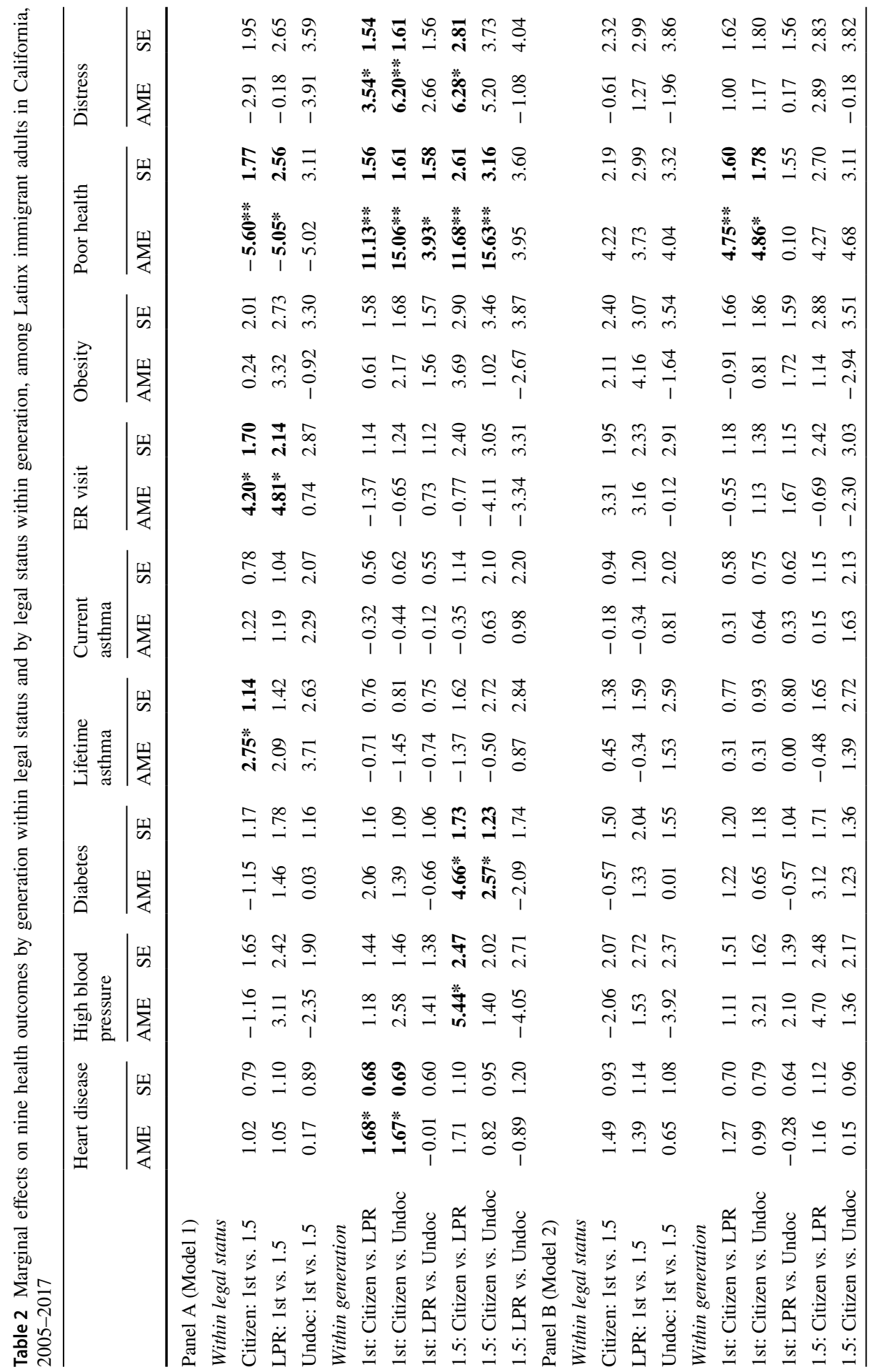




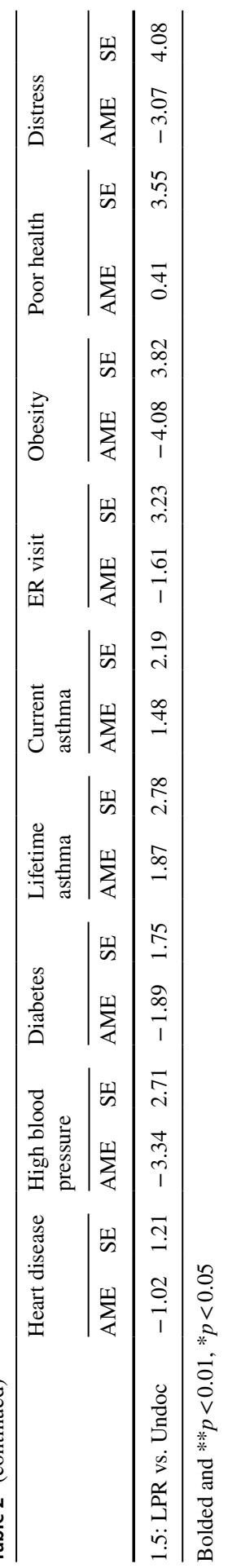


Table 3 Linear probability regression coefficients of nine health outcomes by immigrant legal status, generation, and their interaction among Latinx immigrant adults in California, 2005-2017

\begin{tabular}{|c|c|c|c|c|}
\hline & \multicolumn{2}{|c|}{$\begin{array}{l}\text { Model } 1 \\
\text { Age + Year }\end{array}$} & \multicolumn{2}{|c|}{$\begin{array}{l}\text { Model } 2 \\
\text { All covariates }\end{array}$} \\
\hline & Coeff. & SE & Coeff. & SE \\
\hline \multicolumn{5}{|l|}{ 1.Heart disease } \\
\hline 1.5 generation $(\mathrm{ref}=1 \mathrm{st})$ & 0.010 & $(0.008)$ & 0.015 & $(0.009)$ \\
\hline LPR (ref = citizen) & $0.017 *$ & $(0.007)$ & 0.013 & $(0.007)$ \\
\hline Undoc & $0.017 *$ & $(0.007)$ & 0.010 & $(0.008)$ \\
\hline $\mathrm{LPR} \times 1.5$ & 0.000 & $(0.013)$ & -0.001 & $(0.013)$ \\
\hline Undoc $\times 1.5$ & -0.009 & $(0.012)$ & -0.008 & $(0.012)$ \\
\hline \multicolumn{5}{|l|}{ 2.High blood pressure } \\
\hline 1.5 generation $(\mathrm{ref}=1 \mathrm{st})$ & -0.012 & $(0.017)$ & -0.021 & $(0.021)$ \\
\hline LPR $($ ref $=$ citizen $)$ & 0.012 & $(0.014)$ & 0.011 & $(0.015)$ \\
\hline Undoc & 0.026 & $(0.015)$ & $0.032 *$ & $(0.016)$ \\
\hline $\mathrm{LPR} \times 1.5$ & 0.043 & $(0.029)$ & 0.036 & $(0.028)$ \\
\hline Undoc $\times 1.5$ & -0.012 & $(0.024)$ & -0.019 & $(0.025)$ \\
\hline \multicolumn{5}{|l|}{ 3.Diabetes } \\
\hline 1.5 generation $(\mathrm{ref}=1 \mathrm{st})$ & -0.012 & $(0.012)$ & -0.006 & $(0.015)$ \\
\hline LPR $($ ref $=$ citizen $)$ & 0.021 & $(0.012)$ & 0.012 & $(0.012)$ \\
\hline Undoc & 0.014 & $(0.011)$ & 0.007 & $(0.012)$ \\
\hline $\mathrm{LPR} \times 1.5$ & 0.026 & $(0.021)$ & 0.019 & $(0.020)$ \\
\hline Undoc $\times 1.5$ & 0.012 & $(0.016)$ & 0.006 & $(0.016)$ \\
\hline \multicolumn{5}{|l|}{ 4.Ever asthma } \\
\hline 1.5 generation $(\mathrm{ref}=1 \mathrm{st})$ & $0.028 *$ & $(0.011)$ & 0.005 & $(0.014)$ \\
\hline LPR $($ ref $=$ citizen $)$ & -0.007 & $(0.008)$ & 0.003 & $(0.008)$ \\
\hline Undoc & -0.015 & $(0.008)$ & 0.003 & $(0.009)$ \\
\hline $\mathrm{LPR} \times 1.5$ & -0.007 & $(0.018)$ & -0.008 & $(0.018)$ \\
\hline Undoc $\times 1.5$ & 0.010 & $(0.028)$ & 0.011 & $(0.027)$ \\
\hline \multicolumn{5}{|l|}{ 5.Current asthma } \\
\hline 1.5 generation $(\mathrm{ref}=1 \mathrm{st})$ & 0.012 & $(0.008)$ & -0.002 & $(0.009)$ \\
\hline LPR $($ ref $=$ citizen $)$ & -0.003 & $(0.006)$ & 0.003 & $(0.006)$ \\
\hline Undoc & -0.004 & $(0.006)$ & 0.006 & $(0.008)$ \\
\hline $\mathrm{LPR} \times 1.5$ & -0.000 & $(0.013)$ & -0.002 & $(0.013)$ \\
\hline Undoc $\times 1.5$ & 0.011 & $(0.022)$ & 0.010 & $(0.021)$ \\
\hline \multicolumn{5}{|l|}{ 6.ER visit } \\
\hline 1.5 generation $(\mathrm{ref}=1 \mathrm{st})$ & $0.042 *$ & $(0.017)$ & 0.033 & $(0.020)$ \\
\hline LPR $($ ref $=$ citizen $)$ & -0.014 & $(0.011)$ & -0.006 & $(0.012)$ \\
\hline Undoc & -0.006 & $(0.012)$ & 0.011 & $(0.014)$ \\
\hline $\mathrm{LPR} \times 1.5$ & 0.006 & $(0.027)$ & -0.001 & $(0.026)$ \\
\hline Undoc $\times 1.5$ & -0.035 & $(0.032)$ & -0.034 & $(0.031)$ \\
\hline \multicolumn{5}{|l|}{ 7.Obesity } \\
\hline 1.5 generation $(\mathrm{ref}=1 \mathrm{st})$ & 0.002 & $(0.020)$ & 0.021 & $(0.024)$ \\
\hline LPR $($ ref $=$ citizen $)$ & 0.006 & $(0.016)$ & -0.009 & $(0.017)$ \\
\hline Undoc & 0.022 & $(0.017)$ & 0.008 & $(0.019)$ \\
\hline $\mathrm{LPR} \times 1.5$ & 0.031 & $(0.033)$ & 0.021 & $(0.032)$ \\
\hline
\end{tabular}


Table 3 (continued)

\begin{tabular}{|c|c|c|c|c|}
\hline & \multicolumn{2}{|l|}{$\begin{array}{l}\text { Model } 1 \\
\text { Age + Year }\end{array}$} & \multicolumn{2}{|c|}{$\begin{array}{l}\text { Model } 2 \\
\text { All covariates }\end{array}$} \\
\hline & Coeff. & SE & Coeff. & SE \\
\hline Undoc $\times 1.5$ & -0.012 & $(0.038)$ & -0.038 & $(0.037)$ \\
\hline \multicolumn{5}{|l|}{ 8.Poor health } \\
\hline 1.5 generation $(\mathrm{ref}=1 \mathrm{st})$ & $-0.056^{* *}$ & $(0.018)$ & 0.042 & $(0.022)$ \\
\hline LPR (ref = citizen) & $0.111 * * *$ & $(0.016)$ & $0.048 * *$ & $(0.016)$ \\
\hline Undoc & $0.151 * * *$ & $(0.016)$ & $0.049 * *$ & $(0.018)$ \\
\hline $\mathrm{LPR} \times 1.5$ & 0.006 & $(0.030)$ & -0.005 & $(0.030)$ \\
\hline Undoc $\times 1.5$ & 0.006 & $(0.035)$ & -0.002 & $(0.033)$ \\
\hline \multicolumn{5}{|l|}{ 9.Distress } \\
\hline 1.5 generation $(\mathrm{ref}=1 \mathrm{st})$ & -0.029 & $(0.020)$ & -0.006 & $(0.023)$ \\
\hline LPR (ref= citizen $)$ & $0.035^{*}$ & $(0.015)$ & 0.010 & $(0.016)$ \\
\hline Undoc & $0.062 * * *$ & $(0.016)$ & 0.012 & $(0.018)$ \\
\hline $\mathrm{LPR} \times 1.5$ & 0.027 & $(0.032)$ & 0.019 & $(0.032)$ \\
\hline Undoc $\times 1.5$ & -0.010 & $(0.040)$ & -0.014 & $(0.040)$ \\
\hline
\end{tabular}

\section{Discussion}

In this study, we examined the association between immigrant legal status and nine health outcomes among 23,288 Latinx immigrant adults in the 2005-2017 CHIS, considering differences within and between the 1st and 1.5 immigrant generations. Non-citizen immigrants in the United States face substantial socioeconomic and health care disadvantages that arise from the denial of rights and the significant threat of detention and deportation, and these forces arguably undermine immigrant health. We expected to find legal status differences in health within both generations, but we also expected that the health consequences of non-citizen status would be greater among 1.5-generation immigrants, who grew up in the same society that denies them formal membership.

We find some evidence of legal status disparities in health within the 1 st and 1.5 generations of Latinx immigrant adults in the United States. In the 1st generation, non-citizens have higher rates of heart disease, while in the 1.5 generation, non-citizens have higher rates of high blood pressure and diabetes. In both generations, non-citizens have higher rates of mental distress and poor self-rated health than citizens. We did not find support for our second expectation, which was that legal status disparities in health would be greater among the 1.5 generation. While we do not observe significant generational differences in the association between legal status and health, we do observe different patterns across physical health outcomes. Because the generational patterns of legal status disparities in physical health vary across outcomes, analyses that combine the 1st and 1.5 generations may obscure legal status differences in physical health.

Within both generations, we observe differences in health between citizens and non-citizens, but not among non-citizens. Other studies have found similar patterns 
in educational and labor market settings (Patler, 2018a; Patler et al., Patler, Gleeson, et al., 2020). Although LPR status provides immigrants with greater rights and protections than available to undocumented immigrants, integration into US institutions, including health care, may place immigrants with more stable legal status at risk. Asad (2018) finds that LPRs in Dallas perceive greater vulnerability to deportation than undocumented immigrants due precisely to their system embeddedness, or formal involvement with US institutions. In other words, the inclusion that theoretically gives immigrants with greater legal rights more stability and support in the United States at the same time make LPRs feel more vulnerable. The US immigration regime may be as detrimental to the sense of security and wellbeing of immigrants with permanent resident visas, even though permanent resident visas provide fundamental material and legal protections.

Although we find some evidence of legal status disparities in health on some measures, we do not observe disparities on others. This could reflect the unique context of California in the 2005-2017 period, during which the state passed a number of laws expanding immigrant rights which may have mitigated some disparities we might have otherwise have observed. It is also possible that the absence of consistent health disparities across legal status reflects the racialization of legal status. As Asad and Clair (2018) have argued, undocumented immigration status is racialized to disproportionately impact Latinx immigrants, such that immigration law and enforcement, and the discourse surrounding immigration law, have both direct effects on the health of undocumented immigrants and spillover effects onto documented Latinx immigrants, as well as onto US-born Latinx communities. If this is the case, then legal status as a racialized fundamental cause of health may suppress within-generation differences by legal status. In other words, we may not see a consistent undocumented or non-citizen disadvantage in physical health because the consequences of the discriminatory and enforcement regime against undocumented and other noncitizen immigrants in the United States affect all members of the Latinx immigrant community.

We also find that socioeconomic status and health care fully mediate within-generation legal status disparities in physical health and mental distress. This finding suggests that legal status stratification in socioeconomic opportunities and health care are primary mechanisms through which immigration policy and enforcement undermine immigrant health (see also Bacong \& Sohn, 2020). However, these findings do not rule out the substantial role of stress generated by immigration law and enforcement. For one, disparities in poor self-rated health among the 1st generation persist in spite of controls for socioeconomic and health care, which could indicate the independent role of stress. At the same time, stress arguably impacts the covariates in the model, as multiple studies show that fear of immigration enforcement and stress generated by legal uncertainty and exclusion affect interactions in family life, with health care institutions and providers, in school, and at work (Cardoso et al., 2021; Enriquez et al., 2018; Gándara \& Ee, 2021; Gomez Cervantes and Menjívar, 2020; Valdivia, 2019). In other words, group differences in these mediators may themselves be outcomes of the stress and fear generated by immigration enforcement, and not independent mechanisms of health disparities. 
We find greater evidence of a legal status gradient in health than other studies. This could be because prior studies do not disaggregate by immigrant generation. However, the difference may also owe to study design, including the population studied and the data and key measures used. Two studies using national data-one on Mexican-born farm workers and one on Latinx adults-found evidence of the opposite pattern to ours, that is, of better health among less legally privileged immigrants (Hamilton et al., 2019; Ro \& Van Hook, 2021). It is possible that the difference owes to differences in the composition of immigrants across US states. There may be unique patterns of selectivity into different state destinations, reflecting distinct costs and networks available to migrants. Testing state variation in the association between legal status and health is one of many steps for future research on this topic.

Another important step for research is to incorporate dynamic, retrospective measures of legal status. This study and most others documenting inequality in immigrant health rely on static measures of legal status, but immigrant legal status frequently changes (Flores Morales, 2021). Research on DACA shows that the expansion of legal rights had short-term health benefits for participants and their children (Patler et al., 2019, Patler, Hamilton, et al., 2020). Future research on legal status disparities in immigrant health should also account for changes to legal status across the life course, and how those may influence health.

Acknowledgements We gratefully acknowledge support from the National Science Foundation (Award 1822787) and the UC Davis Academic Senate Faculty Research Grant. We thank Ninez Ponce and the staff at the UCLA Center for Health Policy Research Data Access Center for their generous support and assistance with the analysis of the California Health Interview Survey.

Open Access This article is licensed under a Creative Commons Attribution 4.0 International License, which permits use, sharing, adaptation, distribution and reproduction in any medium or format, as long as you give appropriate credit to the original author(s) and the source, provide a link to the Creative Commons licence, and indicate if changes were made. The images or other third party material in this article are included in the article's Creative Commons licence, unless indicated otherwise in a credit line to the material. If material is not included in the article's Creative Commons licence and your intended use is not permitted by statutory regulation or exceeds the permitted use, you will need to obtain permission directly from the copyright holder. To view a copy of this licence, visit http://creativecommons.org/licen ses/by/4.0/.

\section{References}

Abrego, L. J. (2006). 'I can't go to college because I don't have papers': Incorporation patterns of Latino undocumented youth. Latino Studies, 4(3), 212-231. https://doi.org/10.1057/palgrave.1st.8600200

Abrego, L. J. (2011). Legal consciousness of undocumented Latinos: Fear and stigma as barriers to claims-making for first- and 1.5-generation immigrants: Legal consciousness of undocumented Latinos. Law \& Society Review, 45(2), 337-370. https://doi.org/10.1111/j.1540-5893.2011.00435.x

Amuedo-Dorantes, C., \& Antman, F. (2016). Can authorization reduce poverty among undocumented immigrants? Evidence from the deferred action for childhood arrivals program. Economics Letters, 147, 1-4. https://doi.org/10.1016/j.econlet.2016.08.001

Asad, A. 2018. On the radar: System embeddedness and Latin American immigrants' perceived risk of deportation. SocArSiv. Retrieved December 30, 2019, from https://doi.org/10.31235/osf.io/dcgfw 
Asad, A. L. (2020). Latinos' deportation fears by citizenship and legal status, 2007 to 2018. Proceedings of the National Academy of Sciences, 117(16), 8836-8844. https://doi.org/10.1073/pnas.19154 60117

Asad, A. L., \& Clair, M. (2018). Racialized legal status as a social determinant of health. Social Science \& Medicine, 199, 19-28. https://doi.org/10.1016/j.socscimed.2017.03.010

Bacong, A., \& Sohn, H. (2020). Disentangling contributions of demographic, family, and socioeconomic factors on associations of immigration status and health in the United States. Journal of Epidemiology and Community Health. https://doi.org/10.1136/jech-2020-214245

Bean, F., Brown, S. K., Bachmeier, J. D., Brown, S., \& Bachmeier, J. (2015). Parents without papers: The progress and pitfalls of Mexican American integration. Russell Sage Foundation.

Berk, M. L., \& Schur, C. L. (2001). The effect of fear on access to care among undocumented Latino immigrants. Journal of Immigrant Health, 3(3), 151-156. https://doi.org/10.1023/A:1011389105 821

Borjas, G. J. (2011). Poverty and program participation among immigrant children. The Future of Children, 21(1), 247-266.

Cardoso, J. B., Brabeck, K., Capps, R., Chen, T., Giraldo-Santiago, N., Huertas, A., \& Mayorga, N. A. (2021). Immigration enforcement fear and anxiety in Latinx high school students: The indirect effect of perceived discrimination. Journal of Adolescent Health, 68(5), 961-968.

Castañeda, H., Holmes, S. M., Madrigal, D. S., Young, M.-E., Beyeler, N., \& Quesada, J. (2015). Immigration as a social determinant of health. Annual Review of Public Health, 36(1), 375-392. https:// doi.org/10.1146/annurev-publhealth-032013-182419

Dreby, J. (2015). Everyday illegal: When policies undermine immigrant families. University of California Press.

Enriquez, L. E. (2020). Of love and papers: how immigration policy affects romance and family. University of California Press.

Enriquez, L. E., Hernandez, M., \& Ro, A. (2018). Deconstructing immigrant illegality: A mixed-methods investigation of stress and health among undocumented college students. Race and Social Problems, 10(3), 193-208.

Finch, B. K., \& Vega, W. A. (2003). Acculturation stress, social support, and self-rated health among Latinos in California. Journal of Immigrant Health, 5(3), 109-117. https://doi.org/10.1023/A:10239 87717921

Flores, M. E. S., Simonsen, S. E., Manuck, T. A., Dyer, J. M., \& Turok, D. K. (2012). The 'Latina epidemiologic paradox': Contrasting patterns of adverse birth outcomes in U.S.-born and foreign-born Latinas. Women's Health Issues, 22(5), e501-e507. https://doi.org/10.1016/j.whi.2012.07.005

Flores Morales, J. (2021). Aging and undocumented: The sociology of aging meets immigration status. Sociology Compass, 15(4), e12859. https://doi.org/10.1111/soc4.12859

Gándara, P., \& Ee, J. (2021). Schools under Siege: The impact of immigration enforcement on educational equity. Harvard Education Press.

García, S. J. (2018). Living a deportation threat: Anticipatory stressors confronted by undocumented Mexican immigrant women. Race and Social Problems, 10(3), 221-234. https://doi.org/10.1007/ s12552-018-9244-2

Gleeson, S. (2010). Labor rights for all? The role of undocumented immigrant status for worker claims making. Law and Social Inquiry, 35(3), 561-602.

Gleeson, S., \& Gonzales, R. G. (2012). When do papers matter? An institutional analysis of undocumented life in the United States: When do papers matter? International Migration, 50(4), 1-19. https://doi.org/10.1111/j.1468-2435.2011.00726.x

Gomez Cervantes, A., \& Menjívar, C. (2020). Legal violence, health, and access to care: Latina immigrants in rural and urban Kansas. Journal of Health and Social Behavior, 61(3), 307-323. https:// doi.org/10.1177/0022146520945048

Gonzales, R. G. (2011). Learning to be illegal: Undocumented youth and shifting legal contexts in the transition to adulthood. American Sociological Review, 76(4), 602-619. https://doi.org/10.1177/ 0003122411411901

Gonzales, R. G., \& Chavez, L. R. (2012). 'Awakening to a nightmare': Abjectivity and Illegality in the lives of undocumented 1.5-generation Latino immigrants in the United States. Current Anthropology, 53(3), 255-281. https://doi.org/10.1086/665414

Hamilton, E. R., Hale, J. M., \& Savinar, R. (2019). Immigrant legal status and health: Legal status disparities in chronic conditions and musculoskeletal pain among Mexican-born farm workers in the United States. Demography, 56(1), 1-24. https://doi.org/10.1007/s13524-018-0746-8 
Harris, K. M. (2010). An integrative approach to health. Demography, 47(1), 1-22. https://doi.org/10. 1353/dem.0.0091

Hummer, R. A., \& Hamilton, E. R. (2019). Population health in America. UC Press.

Iten, A. E., Jacobs, E. A., Lahiff, M., \& Fernández, A. (2014). Undocumented immigration status and diabetes care among Mexican immigrants in two immigration 'sanctuary' areas. Journal of Immigrant and Minority Health, 16(2), 229-238. https://doi.org/10.1007/s10903-012-9741-0

Joseph, T. 2020. The documentation status continuum: Citizenship and increasing stratification in American life.

Kelaher, M., \& Jessop, D. J. (2002). Differences in low-birthweight among documented and undocumented foreign-born and US-born Latinas. Social Science \& Medicine, 55(12), 2171-2175. https://doi.org/10.1016/S0277-9536(01)00360-4

Link, B. G., \& Phelan, Jo. (1995). Social conditions as fundamental causes of disease. Journal of Health and Social Behavior, 35, 80. https://doi.org/10.2307/2626958

Lopez, W. D. (2019). Separated: Family and community in the aftermath of an immigration raid. JHU Press.

Marshall, K. J., Urrutia-Rojas, X., Mas, F. S., \& Coggin, C. (2005). Health status and access to health care of documented and undocumented immigrant Latino women. Health Care for Women International, 26(10), 916-936. https://doi.org/10.1080/07399330500301846

Martinez, O., Elwin, Wu., Sandfort, T., Dodge, B., Carballo-Dieguez, A., Pinto, R., Rhodes, S., Moya, E., \& Chavez-Baray, S. (2015). Evaluating the impact of immigration policies on health status among undocumented immigrants: A systematic review. Journal of Immigrant and Minority Health, 17(3), 947-970. https://doi.org/10.1007/s10903-013-9968-4

Menjívar, C. (2006). Liminal Legality: Salvadoran and Guatemalan Immigrants' Lives in the United States. American Journal of Sociology, 111(4), 999-1037. https://doi.org/10.1086/499509.

Menjívar, C., \& Abrego, L. J. (2012). Legal violence: Immigration law and the lives of central American immigrants. American Journal of Sociology, 117(5), 1380-1421. https://doi.org/10.1086/ 663575

Migration Policy Institute. (2021). Data Hub. https://www.migrationpolicy.org/. Accessed 10 Jan 2021.

Novak, N., Geronimus, A., \& Martinez-Cardoso, A. (2017). Change in birth outcomes among infants born to Latina mothers after a major immigration raid. International Journal of Epidemiology, 46(3), 839-849. https://doi.org/10.1093/ije/dyw346

Oropesa, R. S., Landale, N. S., \& Hillemeier, M. M. (2015). Family legal status and health: Measurement dilemmas in studies of Mexican-origin children. Social Science \& Medicine, 138, 57-67. https://doi.org/10.1016/j.socscimed.2015.05.038

Patler, C. (2018a). Citizen advantage, undocumented disadvantage, or both? The comparative educational outcomes of second and 1.5-generation Latino young adults ${ }^{1}$. International Migration Review, 52(4), 1080-1110. https://doi.org/10.1177/0197918318781847

Patler, C. (2018b). To reveal or conceal: How diverse undocumented youth navigate legal status disclosure. Sociological Perspectives. https://doi.org/10.1177/0731121418775092

Patler, C., Gleeson, S., \& Schonlau, M. (2020). Contesting inequality: The impact of immigrant legal status and education on legal knowledge and claims-making in low-wage labor markets. Social Problems. https://doi.org/10.1093/socpro/spaa029

Patler, C., Hamilton, E., \& Savinar, R. (2020). The limits of gaining rights while remaining marginalized: The deferred action for childhood arrivals (DACA) program and the psychological wellbeing of Latina/o undocumented youth. Social Forces. https://doi.org/10.1093/sf/soaa099

Patler, C., Hamilton, E., Meagher, K., \& Savinar, R. (2019). Uncertainty about DACA may undermine its positive impact on health for recipients and their children. Health Affairs, 38(5), 738-745. https://doi.org/10.1377/hlthaff.2018.05495

Patler, C., \& Pirtle, W. L. (2018). From undocumented to lawfully present: Do changes to legal status impact psychological wellbeing among Latino immigrant young adults? Social Science \& Medicine, 199, 39-48. https://doi.org/10.1016/j.socscimed.2017.03.009

Phillips, J. A., \& Massey, D. S. (1999). The new labor market: Immigrants and wages after IRCA. Demography, 36(2), 233. https://doi.org/10.2307/2648111

Pourat, N., Wallace, S. P., Hadler, M. W., \& Ponce, N. (2014). Assessing health care services used by California's undocumented immigrant population in 2010. Health Affairs, 33(5), 840-847. https://doi.org/10.1377/hlthaff.2013.0615 
Prochaska, J. J., Hai-Yen, S., Wendy, M., Yanling, S., \& Michael, K. O. (2012). Validity study of the K6 scale as a measure of moderate mental distress based on mental health treatment need and utilization. International Jounral of Methods in Psychiatric Research, 21, 88-97.

Radford, J. 2019. Key findings about U.S. immigration. Factank. Retrieved December 30, 2019, from https://www.pewresearch.org/fact-tank/2019/06/17/key-findings-about-u-s-immigrants/

Ro, A., Bruckner, T., \& Duquette-Rury, L. (2020). Immigrant apprehensions and birth outcomes: Evidence from California birth records 2008-2015. Social Science \& Medicine, 249, 112849.

Ro, A., \& Van Hook, J. (2021). Comparing immigration status and health patterns between Latinos and Asians: Evidence from the survey of income and program participation. PLoS ONE, 16(2), e0246239. https://doi.org/10.1371/journal.pone.0246239

Rumbaut, R. (2004). Ages, life stages, and generational cohorts: Decomposing the immigrant first and second generations in the United States. International Migration Review, 38(3), 1160-1205.

Swartz, J. J., Hainmueller, J., Lawrence, D., \& Rodriguez, M. I. (2017). Expanding prenatal care to unauthorized immigrant women and the effects on infant health. Obstetrics \& Gynecology, 130(5), 938945. https://doi.org/10.1097/AOG.0000000000002275

Taylor, C. J. (2020). Health consequences of laws and public policies that target, or protect, marginalized populations. Sociology Compass, 14(2), e12753. https://doi.org/10.1111/soc4.12753

Torche, F., \& Sirois, C. (2019). Restrictive immigration law and birth outcomes of immigrant women. American Journal of Epidemiology, 188(1), 24-33. https://doi.org/10.1093/aje/kwy218

Torres, J., \& Young, M. E. D. T. (2016). A life-course perspective on legal status stratification and health. SSM, 2, 141-148.

Valdivia, C. (2019). Expanding geographies of deportability: How immigration enforcement at the local level affects undocumented and mixed-status families. Law \& Policy, 41(1), 103-119.

Vaquera, E., Aranda, E., \& Sousa-Rodriguez, I. (2017). Emotional challenges of undocumented young adults: Ontological security, emotional capital, and well-being. Social Problems, 64(2), 298-314. https://doi.org/10.1093/socpro/spx010

Vargas Bustamante, A., Fang, H., Garza, J., Carter-Pokras, O., Wallace, S. P., Rizzo, J. A., \& Ortega, A. N. (2012). Variations in healthcare access and utilization among Mexican immigrants: The role of documentation status. Journal of Immigrant and Minority Health, 14(1), 146-155. https://doi.org/ 10.1007/s10903-010-9406-9

Waters, M. C., Pineau, M. G., \& Academies, N. (Eds.). (2015). The integration of immigrants into American Society: Panel on the integration of immigrants into American Society. The National Academies Press.

Wen, M., \& Maloney, T. N. (2014). Neighborhood socioeconomic status and BMI differences by immigrant and legal status: Evidence from Utah. Economics \& Human Biology, 12, 120-131. https://doi. org/10.1016/j.ehb.2013.03.008

Young, M. E. D. T., \& Pebley, A. R. (2017). Legal status, time in the USA, and the well-being of Latinos in Los Angeles. Journal of Urban Health, 94(6), 764-775. https://doi.org/10.1007/ s11524-017-0197-3

Zayas, L. H., Aguilar-Gaxiola, S., Yoon, H., \& Rey, G. N. (2015). The distress of citizen-children with detained and deported parents. Journal of Child and Family Studies, 24(11), 3213-3223. https://doi. org/10.1007/s10826-015-0124-8

Zong, J., Jeanne, B., \& Micayla, B. (2019). Frequently Requested Statistics on Immigrants and Immigration in the United States. Spotlight. Retrieved December 30, 2019. https:/www.migrationpolicy.org/ article/frequently-requested-statistics-immigrants-and-immigration-unitedstates\#Permanent

Publisher's Note Springer Nature remains neutral with regard to jurisdictional claims in published maps and institutional affiliations. 